\title{
Componentes de rendimento e produtividade de híbridos de milho em função de doses de NPK e de deficit hídrico em estádios fenológicos críticos
}

\author{
Yield components and productivity of maize hybrids in function of NPK doses and drought stress in the critical \\ phenological stages
}

\section{Osmar Henrique de Castro Pias ${ }^{1 *}$, Marcio André Lowe², Junior Melo Damian³, Antônio Luis Santi² e Renato Trevisan ${ }^{2}$}

Submissão: 21/10/2015 / Aceite: 03/05/2017

\section{RESUMO}

O deficit hídrico e a deficiência nutricional são os principais fatores limitantes da produtividade da cultura do milho. Nesse sentido, objetivou-se com este estudo, avaliar os componentes de rendimento e a produtividade de grãos de híbridos de milho em função de níveis de adubação e de deficit hídrico em dois estádios fenológicos. O estudo foi realizado em casa de vegetação com a utilização de vasos com capacidade de 15 L. Utilizou-se delineamento de blocos casualizados em esquema fatorial $(3 \times 4 \times 3)$ com três repetições. Os fatores foram constituídos por híbridos de milho (P30F53, AS1551 e AG5011), níveis de adubação $(0 ; 0,5 ; 1$ e 1,5 vezes a dose recomendada) e deficits hídrico (sem deficit, deficit no pendoamento (VT) e no enchimento de grãos (R2). Foi avaliado a altura de plantas, diâmetro de colmo, número de espigas, comprimento de espigas, massa seca e produtividade de grãos. Independente do híbrido e para todas as variáveis avaliadas a cultura do milho é mais sensível ao deficit hídrico no pendoamento do que no período de enchimento de grãos. O híbrido AS1551 foi o que apresentou maior produtividade de grãos, assim como, se destacou como o mais tolerante ao deficit hídrico e nutricional. A ausência de aplicação de NPK restringiu severamente a produtividade de grãos da cultura do milho, sendo que com o incremento dos níveis de adubação houveram significativos aumentos de produtividade. A correta fertilização do solo nos híbridos AS1551 e AG5011 mitigou os efeitos do deficit hídrico quando aplicado no estádio de enchimento de grãos.

PALAVRAS-CHAVE: adubação, desenvolvimento fenológico, estiagem, rendimento de grãos, Zea mays.

\begin{abstract}
Water stress and nutritional deficiency are the main factors that affecting grain yield of maize crops. In this sense, the aim of this study was to evaluate the yield components and productivity of maize hybrids through the use of fertilizer levels and drought stress at different periods of the reproductive stage. The study was carried out in a greenhouse using plastic vases with 15 liter capacity. A randomized block design in a factorial scheme $(3 \times 4 \times 3)$ with three repetitions was used. The factors were constituted by maize hybrids (P30F53, AS1551 and AG5011), fertilization levels $(0,0.5,1$ and 1.5 times the recommended dose) and drought stress (without deficit, deficit in tasseling (VT) and grain filling (R2). The plant height, stem diameter, number of spikes, spike length, dry matter and grain yield were evaluated. Regardless of hybrid, maize crop is more tolerant to water stress at the tasseling period when compared to grain filling stage. The AS1551 hybrid showed the most grain yield as well as being more tolerant to drought water and malnutrition. The non-application of NPK fertilizer restricted severely grain yield, and with increasing doses there was a significant increase in productivity. The proper soil fertilization in AS1551 and AG5011 hybrids mitigate the effects of drought stress when applied at grain filling stage.
\end{abstract}

KEYWORDS: drought, fertilization, phenological development, grain yield, Zea mays.

${ }^{1}$ Universidade Federal do Rio Grande do Sul, Porto Alegre, RS, Brasil.

${ }^{2}$ Universidade Federal de Santa Maria, Frederico Westphalen, RS, Brasil.

${ }^{3}$ Universidade de São Paulo, Piracicaba, SP, Brasil.

*Autor para correspondência <henriquepias@yahoo.com.br> 


\section{INTRODUÇ̃̃O}

A cultura do milho (Zea mays L.) se destaca no cenário nacional como uma das principais commodities do agronegócio brasileiro. A região Sul do país é responsável por $35 \%$ da produção nacional. Devido aos ganhos genéticos obtidos pelo melhoramento e ao aperfeiçoamento nas técnicas de manejo, ocorreu considerável aumento de produtividade da cultura do milho ao longo do tempo, sendo que na safra de 2015/16, a média da região Sul foi de $6,1 \mathrm{Mg} \mathrm{ha}^{-1}$ (CONAB 2017). Contudo, esta produtividade média está muito abaixo dos potenciais produtivos dos híbridos disponíveis atualmente. Um dos principais motivos para a obtenção de baixas produtividades na cultura do milho é a baixa aplicação de insumos, principalmente fertilizantes (ADAMI et al. 2012), devido ao seu elevado custo (MONDARDO et al. 2011). O nitrogênio, fósforo e potássio são macronutrientes essenciais para o desenvolvimento da cultura, e, quando ocorre a limitação de um ou mais nutrientes a produtividade é reduzida significativamente, impactando diretamente na rentabilidade da lavoura e lucratividade do produtor.

A água é o principal fator limitante da produção das culturas de grãos (BERGAMASCHI et al. 2004, OUDA et al. 2008). Nas condições meteorológicas brasileiras, o deficit hídrico é o maior responsável pela variabilidade temporal da produtividade de grãos das principais culturas (NIED et al. 2005). No estado do Rio Grande do Sul, apesar de a preciptação normal ser bem distribuída nas quatro estações do ano, no verão as chuvas apresentam maior intensidade e alta variabilidade espacial (NIED et al. 2005). Aliado a isso, a evapotranspiração da cultura do milho é elevada nesse período, sendo assim, é comum ocorrer períodos com deficit hídrico para a cultura resultando em expressiva redução da produtividade de grãos (BERGAMASCHI et al. 2006).

A tolerância do milho ao deficit hídrico está relacionada com o estádio fenológico da cultura e as características genotípicas do híbrido, no que se refere a densidade e comprimento do sistema radicular, índice de área foliar, inclinação das folhas, altura das plantas e regulação fisiológica (ANDRIOLI \& SENTELHAS 2009). A tolerância ao deficit hídrico é uma característica conferida à planta por meio de vários genes, sendo portanto, de difícil manuseio pelo melhoramento genético (BEEVER 2000). Em decorrência disso, observa-se que apesar da sua elevada importância, poucos híbridos têm sido desenvolvido e lançados no mercado com este propósito.

O período mais sensível da cultura do milho ao deficit hídrico situa-se entre o pendoamento (VT) e o enchimento de grãos (R2), pois impacta diretamente na produtividade de grãos, sendo seus danos irreversíveis (BERGAMASCHI et al. 2006). É amplamente reportado na literatura a ocorrência de diferentes graus de tolerância ao deficit hídrico entre genótipos (KAPPES et al. 2010, SOUZA et al. 2016, PIAS et al. 2017). Sendo assim, o estudo de híbridos amplamente cultivados na região Sul é essencial para se buscar maior estabilidade produtiva na cultura do milho (VAZ-DE-MELO et al. 2012), assim como, avaliar a resposta de híbridos a condições de fertilidade pouco favorável conforme ocorre comumente em lavouras do estado do Rio Grande do Sul (BISSANI et al. 2008).

A hipótese que fundamenta esse trabalho é de que híbridos de milho respondem de forma diferenciada a níveis de adubação e deficit hídrico e que a correta fertilização da cultura pode elevar a tolerância do híbrido ao deficit hídrico. Sendo assim, objetivou-se com este estudo, avaliar os componentes de rendimento e produtividade de grãos de híbridos de milho em função de níveis de adubação e de deficit hídrico em dois estádios fenológicos.

\section{MATERIAL E MÉTODOS}

O experimento foi conduzido no ano de 2014, em casa de vegetação climatizada pertencente ao CAFW/UFSM, situada entre a latitude $27^{\circ} 23^{\prime} 45^{\prime \prime S}$ e longitude $53^{\circ} 25^{\prime} 45^{\prime \prime} \mathrm{O}$, com altitude média de 488 $\mathrm{m}$, localizada no municipio de Frederico Westphalen, região do Médio Alto Uruguai, RS, Brasil.

O delineamento experimental utilizado foi o de blocos ao acaso em um arranjo fatorial $(3 \times 4$ x 3) com três repetições, totalizando 108 unidades experimentais as quais foram representadas cada uma por três plantas, cultivadas em vasos separados. $\mathrm{O}$ primeiro fator de variação foram os híbridos simples P30F53 (precose) e AS1551 (superprecose) e o híbrido triplo AG5011 (precose). O segundo fator de variação foram níveis de $0 ; 0,5 ; 1$ e 1,5 vezes a dose recomendada de adubação NPK a partir da análise de solo, segundo o Manual de Adubação e Calagem para estados do RS e SC (CQFS-RS/SC 2004). O último fator foi constituído pela submissão 
dos tratamentos a deficit hídrico, sendo os tratamentos sem restrição hídrica (controle) e com restrição hídrica no pendoamento (VT) e enchimento de grãos (R2) (RITCHIE et al. 1993).

A semeadura da cultura do milho ocorreu no dia 01/10/2014 em vasos com capacidade de $15 \mathrm{~L}$. O solo utilizado foi obtido da camada de 0,00 - 0,10 $\mathrm{m}$ de um Latossolo Vermelho distrófico típico (área agrícola) (SANTOS et al. 2013). Os valores dos principais atributos químicos do solo no momento da implantação do experimento foram: $\mathrm{pH}$ em água (1:1): 5,3; P (Mehlich): $13 \mathrm{mg} \mathrm{kg}^{-1}$; K: $252 \mathrm{mg} \mathrm{kg}^{-1}$; Ca: $3,4 \mathrm{cmol}_{\mathrm{c}} \mathrm{kg}^{-1} ; \mathrm{Mg}$ trocável: $1,7 \mathrm{cmol}_{\mathrm{c}} \mathrm{kg}^{-1} ; \mathrm{Al}$ : $0,6 \mathrm{cmol}_{\mathrm{c}} \mathrm{kg}^{-1}$; CTC (pH 7,0): 8,7 $\mathrm{cmol}_{\mathrm{c}} \mathrm{kg}^{-1}$; argila: $650 \mathrm{~g} \mathrm{~kg}^{-1}$.

Foram semeadas cinco sementes por vaso a uma profundidade de $0,03 \mathrm{~m}$, quando as plantas atingiram estádio V3 procedeu-se o manejo de desbaste, deixando-se apenas uma planta por vaso. A recomendação da adubação foi baseada em uma expectativa de rendimento de $9.000 \mathrm{~kg} \mathrm{ha}^{-1}$. A adubação de base foi realizada a partir da formulação NPK 05-15-10, aplicada de forma incorporada no solo $(0,06 \mathrm{~m})$. As doses aplicadas foram de $0 \mathrm{~kg} \mathrm{ha}^{-1}$ (controle), $250 \mathrm{~kg} \mathrm{ha}^{-1}$ ( 0,5 vezes a dose recomendada), $500 \mathrm{~kg} \mathrm{ha}^{-1}$ (dose recomendada) e $750 \mathrm{~kg} \mathrm{ha}^{-1}$ (1,5 vezes a dose recomendada). Para a adubação nitrogenada de cobertura utilizou-se a ureia (45-00$00)$ como fonte de $\mathrm{N}$, sendo as doses recomendadas de $0 \mathrm{~kg} \mathrm{ha}^{-1}$ (controle), $61,1 \mathrm{~kg} \mathrm{ha}^{-1}(0,5$ vezes a dose recomendada), 122,2 $\mathrm{kg} \mathrm{ha}^{-1}$ (dose recomendada) e $183,3 \mathrm{~kg} \mathrm{ha}^{-1}$ (1,5 vezes a dose recomendada). A dose total foi dividida igualmente em duas aplicações, realizadas de forma superficial nos estádios V4 e V7.

As plantas foram mantidas sobre um regime de irrigação por gotejamento, sendo a quantidade de água adequada de acordo com a evapotranspiração da cultura, calculada a partir dos dados tabelados do manual de irrigação (BERNARDO et al. 2006). A temperatura foi mantida em $25^{\circ} \mathrm{C}$ e a umidade relativa do ar a $80 \%$. Para simular a ocorrência de deficit hídrico, os gotejadores foram retirados dos vasos por um período de 20 dias quando $50 \%$ das plantas atingiram os estádios fenológicos de pendoamento (VT) e enchimento de grãos (R2). Em função do trabalho ter sido conduzido em casa de vegetação, não foi necessário realizar tratamentos fitossanitários, o único trato cultural realizado foi o controle manual de plantas invasoras.

No dia 06/02/2015, quando a cultura atingiu o estádio de maturação fisiológica (R6), todas as plantas foram cortadas no ponto de intersecção entre o sistema radicular e a parte vegetativa, sendo que, em laboratório, se determinou o número de espigas, comprimento de espigas $(\mathrm{cm})$ e altura de plantas (cm) a partir de uma régua graduada, diâmetro do colmo $(\mathrm{cm})$ com auxílio de um paquímetro digital e produtividade de grãos $\left(\mathrm{g}\right.$ planta-1 $\left.{ }^{-1}\right)$ Na sequência as plantas foram trituradas, armazenadas em sacos de papel e alocadas em uma estufa de circulação de ar forçado a uma temperatura de $45{ }^{\circ} \mathrm{C}$, até a obtenção de peso constante das amostras, afim de se proceder a determinação da produção de massa seca (g planta $\left.{ }^{-1}\right)$.

Os dados obtidos foram inicialmente submetidos à análise de variância pelo teste de $\mathrm{F}(\mathrm{p} \leq 0,05)$, quando constatada a interação entre os fatores procedeu-se o desmembramento dos efeitos simples, sendo realizado análise de regressão polinomial para o fator nível de adubação e comparação múltipla de média por Tukey $(p \leq 0,05)$ para os demais fatores de variação (qualitativos). Todas as análises foram realizadas por meio do software estatístico SAS (SAS 1999).

\section{RESULTADOS E DISCUSSÃO}

Houve interação entre os três fatores de variação apenas para a variável produtividade de grãos (Tabela 1). Para o número e comprimento de espigas observou-se interação dupla entre os fatores níveis de adubação e híbridos de milho. Para as demais variáveis houve significância apenas para cada fonte de variação isolada, sendo portanto avaliado os seus efeitos principais.

A altura das plantas de milho foram mais afetadas pelo deficit hídrico no pendoamento, sendo que as plantas nesse tratamento tiveram uma altura média de 2,02 m, enquanto os tratamentos com deficit hídrico no enchimento de grãos e sem deficit hídrico obtiveram alturas de 2,23 e $2,25 \mathrm{~m}$, respectivamente (Tabela 2). CARLESSO \& SANTOS (1999) avaliando a cultura do milho sob deficit hídrico em solos com diferentes texturas, observaram uma elevada redução de altura das plantas submetidas ao deficit hídrico principalmente em solos com textura mais argilosa como é o caso do solo utilizado no presente estudo, sendo que esse decréscimo se aproximou a $50 \%$ em relação ao tratamento controle. Essa maior sensibilidade das plantas encontrada pelos autores citados acima, está relacionado com o momento da submissão das plantas ao deficit hídrico, sendo que 
eles aplicaram o deficit hídrico quando as plantas encontravam-se no estádio V2, momento esse em que ocorrem significativos incrementos em altura de plantas.

Ocomprimento de espigas apresentou resultados similares aos obtidos para a altura de plantas, sendo que obteve-se valor médio de $7,20 \mathrm{~cm}$ no tratamento submetido ao deficit hídrico no pendoamento e valores superiores a $8,70 \mathrm{~cm}$ nos demais tratamentos. O período a partir do pendoamento é considerado crítico para a cultura, por ser nesse momento que é formado os principais componenentes de rendimento da cultura (BERGAMASCHI et al. 2006). A aplicação de restrição hídrico nas fases de pendoamento e enchimento de grãos reduziram em 18,24 e 24,36\% a produção de massa seca da cultura do milho em relação ao tratamento controle, repectivamente. Esse resultado corrobora com os encontrados por COSTA et al. (2008) em que estudando duas cultivares de milho aplicando-se restrições hídricas (75 e 50\% de água disponível) no florescimento observaram redução de 20-30\% da produção de massa seca.

Avaliando-se os diferentes híbridos podese observar que o AG5011 foi o que obteve maior desenvolvimento em altura atingindo $2,32 \mathrm{~m}$, se sobrepondo ao P30F53 e ao AS1551 que alcançaram

Tabela 1. Resumo da análise de variância dos componentes de rendimento e produtividade de híbridos $(\mathrm{H})$ de milho em função de níveis de adubação (A) e de deficit hídrico (D) em dois estádios fenológicos. Frederico Westphalen, RS, 2014.

Table 1. Summary of variance analysis for yield components and productivity of maize hybrid (H) in function of fertilizer levels (A) and drought (D) at two phenological stages. Frederico Westphalen, RS, 2014.

\begin{tabular}{lccccccc}
\hline \multicolumn{1}{c}{ FV } & GL & Altura & DC & NE & CE & MS & Prod \\
\hline Bloco & 2 & $\mathrm{~ns}$ & $\mathrm{~ns}$ & $\mathrm{~ns}$ & $\mathrm{~ns}$ & $\mathrm{~ns}$ & $\mathrm{~ns}$ \\
Adubação (A) & 3 & $*$ & $*$ & $*$ & $*$ & $*$ & $*$ \\
Deficit hídrico (D) & 2 & $*$ & $\mathrm{~ns}$ & $\mathrm{~ns}$ & $*$ & $*$ & $*$ \\
A x D & 6 & $\mathrm{~ns}$ & $\mathrm{~ns}$ & $\mathrm{~ns}$ & $\mathrm{~ns}$ & $\mathrm{~ns}$ & $*$ \\
Híbridos (H) & 2 & $*$ & $*$ & $*$ & $*$ & $*$ & $*$ \\
A x H & 6 & $\mathrm{~ns}$ & $\mathrm{~ns}$ & $*$ & $*$ & $\mathrm{~ns}$ & $\mathrm{~ns}$ \\
D x H & 4 & $\mathrm{~ns}$ & $\mathrm{~ns}$ & $\mathrm{~ns}$ & $\mathrm{~ns}$ & $\mathrm{~ns}$ & $\mathrm{~ns}$ \\
A x D x H & 12 & $\mathrm{~ns}$ & $\mathrm{~ns}$ & $\mathrm{~ns}$ & $\mathrm{~ns}$ & $\mathrm{~ns}$ & $*$ \\
CV (\%) & & 7,92 & 10,46 & 27,16 & 20,50 & 23,68 & 41,87 \\
\hline
\end{tabular}

* e ns: significativo e não significativo, respectivamente, em nível de $5 \%$ de probabilidade de erro. $\mathrm{DC}=$ diâmetro de colmo; $\mathrm{NE}=$ número de espigas; $\mathrm{CE}=$ comprimento de espiga; $\mathrm{MS}=$ massa seca e Prod= Produtividade de grãos.

Tabela 2. Valores médios de altura, diâmetro de colmo (DC), comprimento de espiga (CE) e massa seca (MS) da cultura do milho em função da ocorrência de deficit hídrico e níveis de adubação em diferentes híbridos. Frederico Westphalen, RS, 2014.

Table 2. Mean values of plant height, stem diameter (DC), ear length (CE) and dry matter (MS) of the maize in function of fertilizer levels and the occurrence of drought stress in different hybrids. Frederico Westphalen, $R S, 2014$.

\begin{tabular}{|c|c|c|c|c|}
\hline Tratamento & Altura (m) & $\mathrm{DC}(\mathrm{cm})$ & $\mathrm{CE}(\mathrm{cm})$ & MS (g) \\
\hline Sem deficit hídrico & $2,25 \mathrm{a}$ & - & 8,92 a & $122,84 \mathrm{a}$ \\
\hline Pendoamento & $2,02 \mathrm{~b}$ & - & $7,20 \mathrm{~b}$ & $100,44 \mathrm{~b}$ \\
\hline Enchimento de grãos & $2,23 \mathrm{a}$ & - & 8,73 a & $92,92 \mathrm{~b}$ \\
\hline P30F53 & $2,11 \mathrm{~b}$ & $1,25 \mathrm{a}$ & - & $104,56 \mathrm{ab}$ \\
\hline AS1551 & $2,06 \mathrm{~b}$ & $1,14 \mathrm{~b}$ & - & $100,58 \mathrm{~b}$ \\
\hline AG5011 & $2,32 \mathrm{a}$ & $1,18 \mathrm{~b}$ & - & $111,06 \mathrm{a}$ \\
\hline
\end{tabular}

Letras iguais na coluna não diferem pelo teste de Tukey a 5\% de probabilidade de erro. 
2,11 e 2,06 m, respectivamente (Tabela 2). Esse híbrido também foi o que obteve maior produção de massa seca, contudo os seus valores não diferiram estatisticamente do P30F53, e este por sua vez não diferiu do AS1551. As diferenças morfológicas entre o híbrido AG5011 e os demais pode estar relacionada ao primeiro ser um híbrido triplo e os demais híbridos simples. Sendo assim, se espera que o AG5011 seja mais tolerante a estresses (maior rusticidade) e consequentemente menos produtivo que os demais (ARGENTA et al. 2003). Para a variável diâmetro de colmo, o P30F53 foi o que obteve maior desenvolvimento $(1,25 \mathrm{~cm})$ diferenciando-o dos demais híbridos $(<1,18 \mathrm{~cm})$.

A altura das plantas foi altamente afetada pelos níveis de adubação, sendo que no nível 0 de adubação a média foi de 1,35 m (Figura 1a), os dados de altura de plantas se adequaram a uma função quadrática, sendo o ponto de máxima eficiência técnica obtido com o nível de 0,98 vezes a dose de adubo NPK recomendada, na qual onde obteve-se uma altura de $2,52 \mathrm{~m}$, ou seja valor próximo à dose recomendada pelo Manual de Adubação e Calagem para os estados do RS e SC (CQFS-RS/SC 2004).

No nível de adubação 0 (controle) o diâmetro do colo médio foi de $0,83 \mathrm{~cm}$ (Figura $1 \mathrm{~b}$ ), o ponto de máxima eficiência técnica foi de 1,35 vezes a recomendação de adubação, na qual onde as plantas apresentariam um diâmetro médio de $1,40 \mathrm{~cm}$. ADAMI et al. (2012) estudando níveis de adubação orgânica para a cultura do milho também observaram comportamento quadrático do diâmetro de colo, esses mesmos autores citam que plantas que apresentam baixo desenvolvimento de diâmetro de colo e altura consequentemente desenvolvem uma menor área foliar e tem menor capacidade de produção de fotossíntese, impactando diretamente na produtividade de grãos da cultura do milho.

A produção de massa seca se ajustou a uma equação quadrática frente aos incrementos nos níveis de adubação NPK recomendados (Figura 1c). No nível 0 de adubação a produção média de massa seca foi de $63,61 \mathrm{~g}$ planta $^{-1}$, sendo a dose de máxima eficiência técnica de 1,23 vezes a recomendação com uma produção de massa seca de 141,39 g planta $^{-1}$, ou seja, um aumento de produção de massa seca de $122 \%$. O subdesenvolvimento da parte aérea e consequentemente a redução da produção de massa seca é um sintoma característico de plantas com deficiência de nitrogênio, devido principalmente, a redução da produção de proteínas (BISSANI et al. 2008). VALDERRAMA et al. (2011) encontraram resultados contrastantes aos do presente estudo, esses autores estudaram o efeito de doses NPK aplicadas de forma separadas sob a cultura do milho e não encontraram diferenças para as variáveis altura e diâmetro de colmo. Algumas possíveis justificativas para essas diferenças de resultados é de que no presente estudo as plantas foram semeadas em vasos o que pode limitar o seu desenvolvimento radicular, além de a fertilidade do solo utilizado no presente estudo ser inferior a do solo utilizado pelos autores citados acima.

Para a interação entre os níveis de adubação e os híbridos de milho, observou-se que, para o número de espigas houve significância dos híbridos apenas no nível 0 de adubação (controle) (Tabela 3 ). Sendo que, o híbrido AS1551 foi o que apresentou a maior média de número de espigas $(0,63)$, sendo seguido pelo híbrido AG5011 (0,37). Essse resultado nos mostra a grande influência da adubação na produção do milho, pois o híbrido P30F53 praticamente não produziu espigas $(0,07)$ quando não recebeu fertilizante, demonstrando assim a alta exigência nutricional do híbrido. Nos demais níveis de adubação o número de espigas foi semelhante entre os híbridos (próximo a 1 espiga planta $\left.{ }^{-1}\right)$. Este resultado está de acordo com os obtidos por ARGENTA et al. (2003) em que testando cinco níveis de manejo na cultura do milho não observaram diferenças significativas do número de espigas por planta mesmo tendo ocorrido alta variação de produtividade de grãos entre os tratamentos. O comprimento de espigas, no nível de adubação 0, foi significativamente maior para o híbrido AS1551 que obteve uma média de $4,59 \mathrm{~cm}$, sendo esse valor superior aos demais híbridos que apresentaram espigas com comprimento médio inferior a $2 \mathrm{~cm}$. No nível de 0,5 vezes a recomendação, novamente o AS1551 foi superior, porém não diferiu do P30F53. Para os demais níveis de adubação não houve diferença significativa entre os híbridos.

O número de espigas em função dos níveis de adubação se ajustou a equações quadráticas para os híbridos P30F53 e AG5011 (Figura 2a), sendo o ponto de máxima eficiência técnica obtido próximo ao nível de 1 vez a recomendação, aonde os híbridos produziram uma espiga por planta. Já o híbrido AS1551 teve aumento linear com o incremento nos níveis de adubação. 

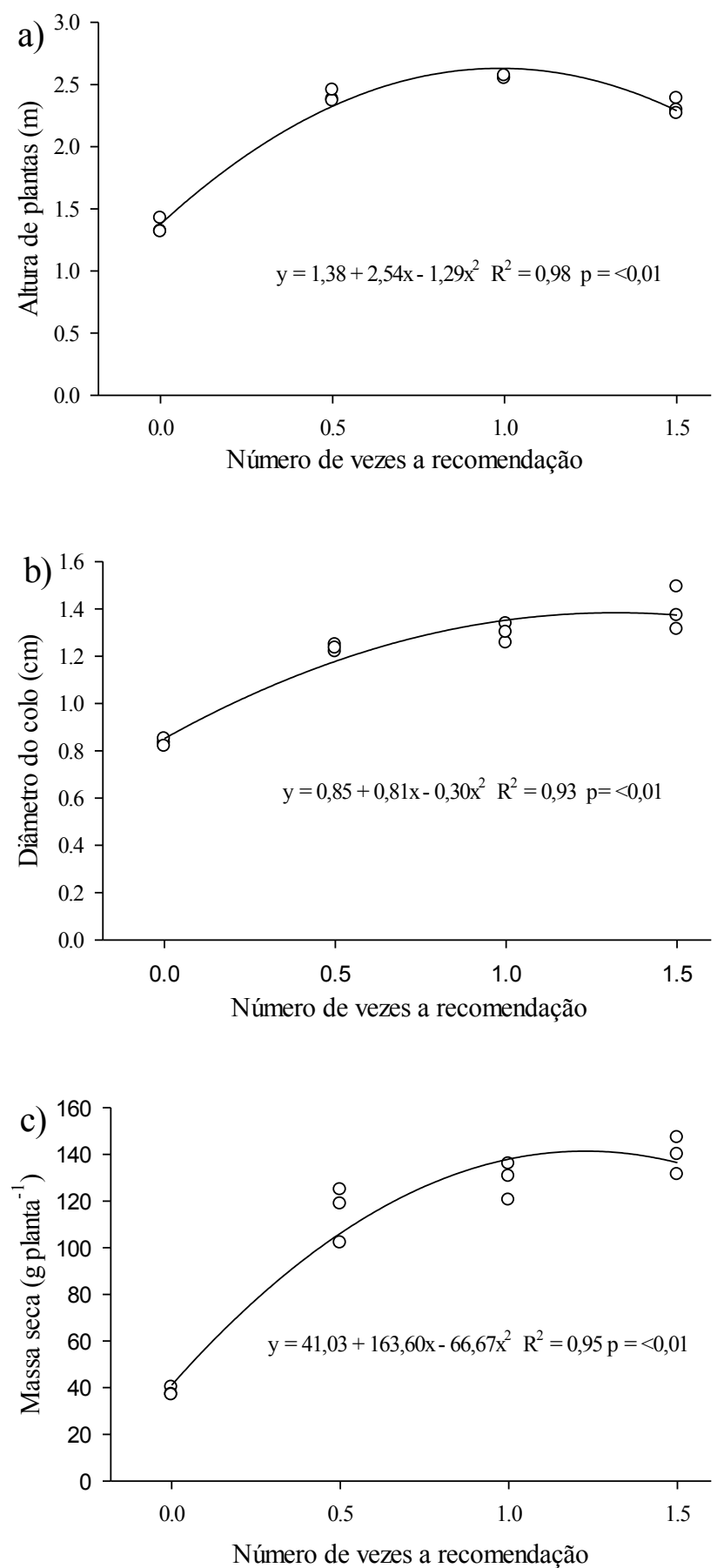

Figura 1. Altura (a), diâmetro de colmo (b) e massa seca (c) de plantas de milho em função de diferentes níveis de adubações. Frederico Westphalen, RS, 2014.

Figure 1. Plant height (a), stem diameter (b) and dry matter (c) of maize plants in function of different levels of fertilization. Frederico Westphalen, RS, 2014. 
Tabela 3. Valores médios do número de espigas e comprimento de espiga dos híbridos de milho em cada nível de adubação. Frederico Westphalen, RS, 2014.

Table 3. Mean values of the number of spikes and length of the cob of maize hybrids in each level of fertilization. Frederico Westphalen, RS, 2014.

\begin{tabular}{|c|c|c|}
\hline Tratamentos & Número de espigas & Comprimento de espigas $(\mathrm{cm})$ \\
\hline & -"------"- & 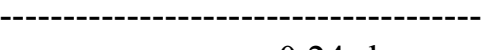 \\
\hline P30F53 & $0,07 \mathrm{C}$ & $0,24 \mathrm{~b}$ \\
\hline AS1551 & $0,63 \mathrm{~A}$ & 4,59 a \\
\hline AG5011 & $0,37 \mathrm{~B}$ & $1,67 \mathrm{~b}$ \\
\hline P30F53 & $0,96^{\mathrm{ns}}$ & $9,56 \mathrm{ab}$ \\
\hline AS1551 & 1,00 & $10,11 \mathrm{a}$ \\
\hline AG5011 & 1,04 & $8,15 \mathrm{~b}$ \\
\hline P30F53 & 0,96 ns & $10,35 \mathrm{~ns}$ \\
\hline AS1551 & 1,00 & 10,43 \\
\hline AG5011 & 1,07 & 10,89 \\
\hline P30F53 & 1,00 ns & $10,86 \mathrm{~ns}$ \\
\hline AS1551 & 1,11 & 11,88 \\
\hline AG5011 & 0,96 & 10,67 \\
\hline
\end{tabular}

${ }^{n}$ Diferenças entre médias não significativas $(\mathrm{p}<0,05)$. Letras iguais na coluna não diferem pelo teste de Tukey a $5 \%$ de probabilidade de erro.
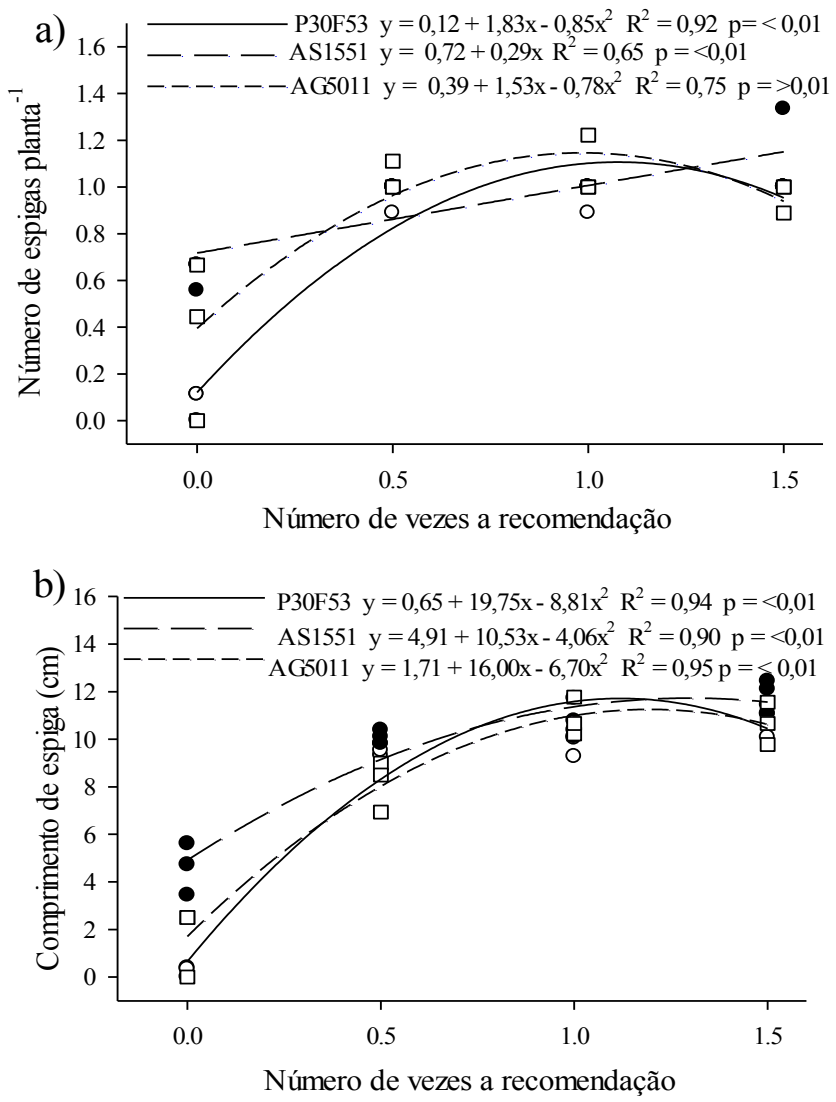

Figura 2. Número de espigas (a) e comprimento de espigas (b) de diferentes híbridos de milho em função de diferentes niveis de adubação. Frederico Westphalen, RS, 2014.

Figure 2. Number of spikes (a) and length (b) of the cob of maize hybrids in function of different level of fertilization. Frederico Westphalen, RS, 2014. 
Todos os híbridos tiveram comportamento quadrático frente aos níveis de adubação para a variável comprimento de espigas, sendo que o ponto de máxima eficiência técnica próximo a 1,2 vezes a recomendação, aonde se produziu espigas com tamanho médio de $11 \mathrm{~cm}$. A principal diferença entre o comportamento do comprimento de espigas entre os híbridos ocorreu no nível de adubação 0 em que o híbrido AS1551 produziu espigas com comprimento médio de 4,6 cm, enquanto os demais híbridos produziram espigas com comprimento médio inferior a $1,7 \mathrm{~cm}$ (Figura 2b).

No nível 0 de adubação praticamente não houve produtividade de grãos, sendo que todos os híbridos produziram menos de $3 \mathrm{~g}$ planta $^{-1}$ (Tabela 4). Já no nível de 0,5 vezes a adubação o tratamento com deficit hídrico no pendoamento foi o menos produtivo para todos os híbridos. Entre os tratamentos sem e com deficit hídrico no enchimento de grãos para o nível de adubação 0,5 vezes a recomendação não houve diferenças de produtividade, com excessão para o híbrido AS1551 em que sem deficit hídrico produziu maior quantidade de grãos. Nos níveis de 1 e 1,5 vezes a recomendação para todos os híbridos as maiores produtividades foram obtidas, respectivamente, nos tratamentos sem deficit hídrico, e com deficit no enchimento de grãos e pendoamento. Esses resultados estão de acordo com os descritos por BERGAMASCHI et al. (2006) em que avaliando o deficit hídrico na cultura do milho por um período de 10 anos concluíram que a fase mais crítica para a cultura é o período de pleno florescimento, pois afeta os componentes de rendimento número de espigas e número de grãos por espiga. Já SOUZA et al. (2016) estudando o efeito do deficit hídrico em dois híbridos nos períodos de pleno florescimento e enchimento de grãos não observaram diferenças entre períodos de restrição para a produtividade de grãos.

Tabela 4. Valores médios de produtividade de grãos $\left(\mathrm{g}\right.$ planta $\left.{ }^{-1}\right)$ em função de diferentes híbridos e deficit hídricos (DH) em cada nível de adubação, Frederico Westphalen, RS, 2014.

Table 4. Mean values of grain yield $\left(g\right.$ plant $\left.^{-1}\right)$ for different hybrids submitted to drought stress $(D H)$ and levels of fertilization, Frederico Westpahlen, RS, 2014.

\begin{tabular}{|c|c|c|c|}
\hline \multirow{2}{*}{ Tratamentos } & \multicolumn{3}{|c|}{ Híbridos de milho } \\
\hline & P30F53 & AS1551 & AG5011 \\
\hline & 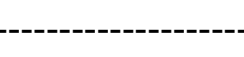 & ---Nível 0---------- & ------------------- \\
\hline Sem DH & $0,28 \mathrm{aB}$ & $2,00 \mathrm{nsA}$ & $1,33 \mathrm{aAB}$ \\
\hline DH no pendoamento & $0,00 \mathrm{bB}$ & $1,22 \quad \mathrm{~A}$ & 1,39 aA \\
\hline $\begin{array}{l}\text { DH no enchimento de } \\
\text { grãos }\end{array}$ & $0,00 \mathrm{bB}$ & $2,72 \quad \mathrm{~A}$ & $0,00 \mathrm{bB}$ \\
\hline Sem DH & 32,78 abB & 41,00 aA & $19,11 \mathrm{aB}$ \\
\hline DH no pendoamento & $2,44 \mathrm{bB}$ & $14,11 \mathrm{bA}$ & $0,00 \mathrm{bB}$ \\
\hline $\begin{array}{l}\text { DH no enchimento de } \\
\text { grãos }\end{array}$ & 24,44 aA & $23,00 \mathrm{bAB}$ & $18,11 \mathrm{aB}$ \\
\hline Sem DH & 63,11 aA & 55,11 aAB & $42,56 \mathrm{aB}$ \\
\hline DH no pendoamento & $2,44 \mathrm{cB}$ & $16,22 \mathrm{cA}$ & $2,52 \mathrm{cB}$ \\
\hline $\begin{array}{l}\text { DH no enchimento de } \\
\text { grãos }\end{array}$ & $19,67 \mathrm{bB}$ & $38,44 \mathrm{bA}$ & $27,56 \mathrm{bAB}$ \\
\hline Sem DH & 65,12 aA & 66,28 aA & 51,33 aA \\
\hline DH no pendoamento & $1,33 \mathrm{cB}$ & $29,78 \mathrm{cA}$ & $0,00 \mathrm{cB}$ \\
\hline $\begin{array}{l}\text { DH no enchimento de } \\
\text { grãos }\end{array}$ & $29,00 \mathrm{bB}$ & 38,17 bA & $34,56 \mathrm{bAB}$ \\
\hline
\end{tabular}

Letras iguais minúsculas na coluna e maíúsculas na linha, não diferem pelo teste de Tukey a $5 \%$ de probabilidade de erro. 

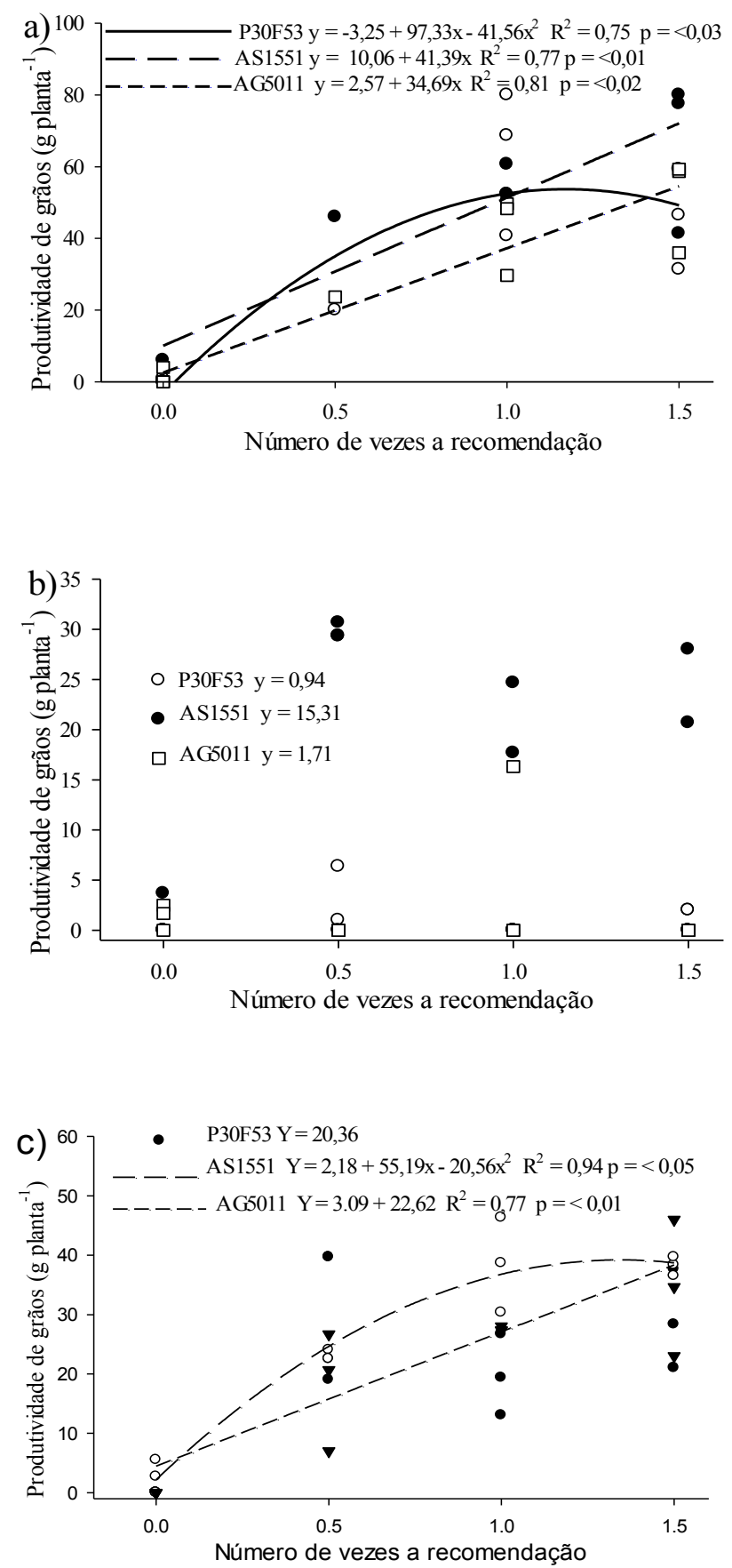

Figura 3. Produtividade de grãos (g planta $\left.{ }^{-1}\right)$ de híbridos de milho submetidos a tratamentos sem deficit hídrico (a) com deficit no pendoamento (b) e no enchimento de grãos (c) em função de diferentes níveis de adubação. Frederico Westphalen, RS, 2014.

Figure 3. Grain yield ( $g$ planta $^{-1}$ ) of maize hybrids submitted to treatments without deficit (a) with a deficit at the tasseling (b) and grain filling (c) in function of different levels offertilization. Frederico Westphalen, $R S, 2014$.

Comparando-se os híbridos, observa-se que o AS1551 se sobrepôs aos demais sendo o mais produtivo, este híbrido apenas não se diferenciou estatisticamente do híbrido P30F53 no tratamento sem deficit hídrico no nível de 1 vez a dose de adubação e do AG5011 no nível de 1,5 vezes a dose de adubação com deficit hídrico no enchimento de grãos. Sendo assim, pode-se inferir que o híbrido AS1551 é o que apresenta maior tolerância a deficit hídrico e nutricional. Em estudo realizado por PIAS et al. (2017) comparando a germinação e vigor de quatro híbridos de milho em substratos com diferentes 
potenciais osmóticos, os autores observaram que o híbrido AS1551 foi o que apresentou maior tolerância ao déficit hídrico, corroborando com os resultados do presente estudo. COSTA et al. (2008) e SOUZA et al. (2016) avaliando cultivares e híbridos de milho também observaram diferenças de tolerâncias entre os materias, demonstrando a importância desse tipo de avaliação para que se possa posicionar esses materiais tolerantes em locais mais suscetíveis à ocorrência de deficit hídrico. Estudos recentes tem demonstrado que os principais fatores que diferenciaram híbridos mais tolerante ao deficit hídrico é o desenvolvimento de um sistema radicular mais vigoroso, com predominância de raízes finas (SOUZA et al. 2016). No presente estudo não foi avaliado o sistema radicular dos híbridos, sendo que, as variáveis biométricas avaliadas (altura, diâmetro de colo e produção de massa seca) não explicam a maior produtividade do híbrido AS1551.

A produtividade de grãos dos híbridos AS1551 e AG5011 no tratamento sem deficit hídrico obtiveram aumento linear com o incremento dos níveis de adubação (Figura 3a), porém destaca-se que o AS1551 foi mais produtivo em todos os níveis de adubação. Esses resultados corroboram com os reportados por RAMBO et al. (2011) que também observaram comportamento linear da cultura do milho frente a incrementos na aplicação de nitrogênio. Já o híbrido P30F53 apresentou um comportamento quadrático, sendo o ponto de máxima eficiência técnica o nível de 1,17 vezes a dose de adubo recomendada.

Nos tratamentos submetidos ao deficit hídrico no pendoamento os níveis de adubação não tiveram influência significativa na produtividade de grãos, sendo que os mesmos não se ajustaram a nenhum modelo (Figura $3 b$ ). Esse resultado pode ser explicado por efeito da restrição hídrica ter sido tão pronunciado na redução de produtividade de grãos que o aumento da disponibilidade de nutrientes não foi eficiente em aumentar a produtividade dos híbridos. No período de florescimento a cultura do milho encontra-se com um alto índice de área foliar, sendo assim, a exigência hídrica é muito elevada, deficit hídrico nesse momento retarda a emissão das inflorescências, prejudicando a polinização e por conseguinte reduzindo o número de grãos por espiga (NIED et al. 2005). Para a produtividade de grãos nos tratamentos submetidos ao deficit hídrico no período de enchimento de grãos o híbrido AS1551 apresentou comportamento quadrático frente aos níveis de adubação, sendo o ponto de máxima eficiência técnica de 1,34 vezes a recomendação (Figura 3c). Já o híbrido AG5011 teve comportamento linear frente aos níveis de adubação. A produtividade de grãos do híbrido P30F53 em função dos incrementos nos níveis de adubação não se ajustou a nenhuma equação.

Diante do exposto, pode-se inferir que dependendo do estádio fenológico da cultura e do híbrido de milho a utilização de uma boa fertilização do solo é capaz de atenuar os efeitos do deficit hídrico. Contudo, quando o deficit hídrico ocorre em estádio crítico para a cultura do milho (VT) este limita severamente a produtividade de grãos, e concequentemente, a maior disponibilidade de nutrientes não é capaz de mitigar tal efeito.

\section{CONCLUSÕES}

Independente do híbrido e para todas as variáveis avaliadas a cultura do milho é mais sensível ao deficit hídrico no pendoamento (VT) do que no período de enchimento de grãos (R2).

O híbrido AS1551 foi o que apresentou maior produtvidade de grãos, assim como, se destacou como o mais tolerante ao deficit hídrico e nutricional.

A ausência de aplicação de NPK restringiu severamente a produtividade de grãos da cultura do milho, sendo que com o incremento dos níveis de adubação houveram significativos aumentos de produtividade.

A correta fertilização do solo nos híbridos AS1551 e AG5011 mitigou os efeitos do deficit hídrico quando aplicado no estádio de enchimento de grãos.

\section{REFERÊNCIAS}

ADAMI PF et al. 2012. Grazing intensities and poultry litter fertilization levels on corn and black oat yield. Pesquisa Agropecuária Brasileira 47: 360-368.

ANDRIOLI KG \& SENTELHAS PC. 2009. Brazilian maize genotypes sensitivity to water deficit estimated through a simple crop yield model. Pesquisa Agropecuária Brasileira 44: 653-660.

ARGENTA $G$ et al. 2003. Potencial de rendimento de grãos de milho em dois ambientes e cinco sistemas de produção. Scientia Agraria 4: 27-34.

BEEVER D. 2000. Os transgênicos e o futuro da agricultura. Biotecnologia Ciência e Desenvolvimento 3: 4-8.

BERGAMASCHI $\mathrm{H}$ et al. 2004. Distribuição hídrica no período crítico do milho e produção de grãos. Pesquisa Agropecuária Brasileira 39: 831-839.

BERGAMASCHI $\mathrm{H}$ et al. 2006. Deficit hídrico e 
produtividade na cultura do milho. Pesquisa Agropecuária Brasileira 41: 243-249.

BERNARDO S et al. 2006. Manual de Irrigação. 8.ed. Viçosa: Editora UFV. 625p.

BISSANI CA et al. 2008. Fertilidade dos solos e manejo da adubação de culturas. 2.ed. Porto Alegre: Metrópole. 344p. CARLESSO R \& SANTOS RF. 1999. Crescimento de plantas de milho submetidas a déficit hídrico em solos de diferentes texturas. Revista Brasileira de Ciência do Solo 23: $27-33$.

CONAB - Companhia Nacional de Abastecimento. 2017. Safras históricas. Disponível em: http://www. conab.gov.br/conteudos.php? $\mathrm{a}=1252 \& \mathrm{t}=2 \&$ Pagina objcmsconteudos=3\#A_objcmsconteudos. Acesso em: 02 abr. 2017.

COSTA JR et al. 2008. Produção de matéria seca de cultivares de milho sob diferentes níveis de estresse hídrico. Revista Brasileira de Engenharia Agrícola e Ambiental 12: 443-450.

CQFS-RS/SC. 2004. Comissão de Química e Fertilidade do Solo. Manual de adubação e calagem para os Estados do Rio Grande do Sul e Santa Catarina. 10.ed. Porto Alegre: Sociedade Brasileira de Ciência do Solo. 400p.

KAPPES C et al. 2010. Germinação, vigor de sementes e crescimento de plântulas de milho sob condições de déficit hídrico. Scientia Agraria 11: 125-134.

MONDARDO D et al. 2011. Produção e composição químico-bromatológica da aveia preta fertilizada com doses crescentes de dejeto líquido suíno. Revista Ciência Agronômica 42:509-517.

NIED AH et al. 2005. Épocas de semeadura do milho com menor risco de ocorrência de deficiência hídrica no município de Santa Maria, RS, Brasil. Ciência Rural 35: 995-1002.

OUDA SAEF et al. 2008. Modeling the effect of different stress conditions on maize productivity using yield stress model. International Journal of Natural \& Engineering Sciences 2: 57-62.

PIAS OH de $\mathrm{C}$ et al. 2017. Germination and vigor of maize hybrids seeds submitted to water stress. Acta Iguazu 6: $1-13$.

RAMBO L et al. 2011. Índices nutricionais de $\mathrm{N}$ e produtividade de milho em diferentes níveis de manejo e de adubação nitrogenada. Pesquisa Agropecuária Brasileira 46: 390-397.

RITCHIE SW et al. 1993. How a corn plant develops. Ames, Iowa State University of Science and Technology, 26p. (Special Report, 48).

SAS INSTITUTE. 1999. Statistical Analysis System, SAS/ STAT User's Guide 8,0, North Caroline, NC: SAS Institute Inc.

SANTOS HG et al. 2013. Sistema Brasileiro de Classificação de Solos. 3.ed. Brasília: Embrapa. 353p.

SOUZA TC et al. 2016. Corn root morphoanatomy at different development stages and yield under water stress.
Pesquisa Agropecuária Brasileira 51: 330-339.

VALDERRAMA M et al. 2011. Fontes e doses de NPK em milho irrigado sob plantio direto. Pesquisa Agropecuária Tropical 41: 254-263.

VAZ-DE-MELO A et al. 2012. Germinação e vigor de sementes de milho-pipoca submetidas ao estresse térmico e hídrico. Bioscience Journal 28: 687-695. 